\title{
Mortality of glass filament (textile) workers
}

\author{
Harry S Shannon, Ellen Jamieson, Jim A Julian, David C F Muir
}

\begin{abstract}
A historical prospective mortality study was conducted at a glass filament plant in Ontario, Canada. The cohort consisted of 1465 men and women who had worked for a total of at least one year between 1951 (when the operations began) and 1986 . Ninety six deaths were found in the $96 \%$ of persons traced. Mortality was compared by the person-years method with that of the Ontario population. An estimate of cumulative dust exposure was made based on long term employees' recollections of past conditions. Overall mortality was below that expected (standardised mortality ratio $(S M R)=76)$ based on 82 deaths. There were 11 deaths due to lung cancer; slightly but not significantly more than expected (SMR $=136$, $\mathbf{p}=0.31$ ). Analysis by both duration of employment and cumulative exposure showed this increase to be inconsistent with an occupational aetiology.
\end{abstract}

After a conference on the effects of manmade mineral fibres (MMMF) a review by Doll concluded that, while there had been an increase in risk of lung cancer for certain workers employed in rock or slag wool and glass wool sectors of the MMMF industry, no risk had been demonstrated in the glass filament industry. ${ }^{1}$ This conclusion was based on results from subcohorts of two major studies that found a total of 79 deaths from lung cancer in filament workers; somewhat fewer than expected $(S M R=93) .^{23}$ Among the studies of glass wool workers was one at a plant in Sarnia, Ontario, Canada, that found a higher SMR for lung cancer compared with that found elsewhere. ${ }^{4}$ The company also owned a glass filament plant and we decided to study workers there. Of particular interest were the incidence of lung cancer and, to a lesser extent, non-malignant respiratory disease.

Occupational Health Program, McMaster University Health Sciences Centre, Hamilton, Ontario L8N 3Z5, Canada

H S Shannon, E Jamieson, J A Julian, D C F Muir

\section{Material and methods}

SITE OF STUDY

The study was conducted at a glass filament plant in Guelph, Ontario, Canada, which opened in 1951 with 35 hourly rated employees, and currently has about 500 . The process involves drawing liquid glass through bushing plates to create filaments $6-24 \mu \mathrm{m}$ diameter. These are sized and wound into packages. Subsequent processing (such as chopping, braiding, twisting, and plying) is also carried out at the plant.

\section{STUDY POPULATION}

We studied all hourly rated and salaried workers who had been employed for a total of at least one year at any time between the opening of the plant and the end of 1986. Personal data and histories of work for hourly rated workers were virtually complete from 1951 onward (preliminary audit showed $5 \%$ missing in $1955,1.5 \%$ in 1966 , and less than $1 \%$ in 1974). The completeness of the cohort was verified by using union seniority lists and company payroll ledgers, checked on average every 18 months over the lifetime of the plant. According to these checks no one with more than one year's employment had been missed from the cohort.

\section{WORK HISTORIES}

Two employees who were hourly rated had no recorded work histories. These were reconstructed by relating wage scales to jobs performed and checking information with coworkers who were still employed at the plant.

Records for salaried staff were not as complete as those for hourly rated personnel. Some 140 individuals' records were missing from the files of former employees but this information was subsequently found on payroll records. These records, dating from the opening of the plant, enabled us to check that the list of salaried workers was complete. Work histories were reconstructed for 20 salaried staff. All but one (who was in quality control) worked in the office area.

Personal identifying data (full name, date of birth, last known address) and work histories were entered into a data base. An audit to determine error rates for personal data and work history was carried out on a sample of 100 records randomly selected from the 
personnel data file; there were no errors in the surnames, dates of birth, or sex. One given name had been recorded in its shortened form; one middle name misspelled; and there were seven instances when only the middle initial was recorded rather than the full middle name. For the work history, a sample of 50 individuals (having a total of 545 work history entries) was checked; incorrectly coded departments (3), incorrect dates (3), and missing entries (4) combined to create an error rate of $0.4 \%$ in the sample. This was considered acceptably low.

\section{MORTALITY ASCERTAINMENT}

About 475 subjects were current employees at the end of the study. Vital status for the remainder was determined by various methods. The Ministry of Transportation and Communication (driver licensing) ran a computerised linkage of our subject file and their file of licensed drivers. We also carried out an on line search of this data base, and of the vehicle registration file (the advantage of the second of these is that renewal of licence plates is required every year, whereas drivers' licences are renewable every three years). Licensing bureaux in other provinces were also contacted. Those whose vital status still remained unknown were traced manually. A mailing was sent to the last known address; a list of untraced individuals was sent to all current employees; and this list was also published in the company newsletter.

The Vital Statistics and Disease Registries Branch of Statistics Canada carried out a manual microfiche search of the National Mortality Data Base on a portion of the cohort that included all untraced individuals. It also included those found, by tracing, to have died as this provided information on the certified cause and date of death of these subjects. A search was also carried out on a sample of those known, by tracing, to be alive. This search confirmed the accuracy of the follow up. All information regarding death rates and causes were taken from death certificates. Certificates were obtained for two deaths that occurred outside Canada (United States and Germany).

\section{ENVIRONMENTAL DATA}

Data on the history of exposure to dust were not available for the plant until 1978 and previous dust concentrations were estimated. A report detailing the development of the plant was compiled including expansions, processes and products, and ventilation changes. Two groups of employees were assembled -one consisting of five union members and one of five staff members-who estimated dustiness for individual jobs and departments over time on a scale from 0 (fresh air) to five (the dustiest conditions ever experienced). When there was disagreement, estimates were averaged.
ANALYSIS

We used the person-years approach described by Case and Lea. ${ }^{5}$ SMRs were calculated with adjust $-\bar{C}$ ment for age, sex, and period. Allowance was also흐 made for duration of employment and time since first $\overline{\bar{A}}$ : work, by moving subjects through a series of categories depending on their cumulative exposure and years since first exposure. The standard popula- $\infty$ tion used was that of Ontario. Two sided statistical $\overrightarrow{0}$ tests on the SMR were calculated assuming the normal approximation when the expected number of deaths was greater than five and the Poisson distribu-Oำ tion for smaller values. The primary significance $\frac{\mathbb{D}}{3}$ level was $5 \%$.

More detailed analyses omitted the first five years ${ }_{00}$ after exposure as we assumed that no death from lungic cancer due to exposure could have occurred in that $\omega$ time. Similarly, the last five years of exposure up to윽 the point of analysis were ignored in some calcula- tions (a five year lag), as fibres inhaled during that period were not likely to contribute to mortality.

\section{ADMINISTRATIVE ARRANGEMENTS}

The study team worked directly with a steering committee at the plant, made up of three management and three union representatives. Theo protocol was discussed in advance with the committee, and progress reports and results were presented to it initially for comments.

\section{Results}

All but 64 subjects were traced, giving a follow up success of $95 \cdot 6 \%$. Those not found were included in a search of the National Mortality Database (NMDB) at Statistics Canada, and if they had died in Canada@ they were likely to have been identified as dead. The? effective trace rate was thus greater than the $95.6 \%$

Table 1 Person-years of observation among employees (1951-86) by age and time since first exposure to dust

\begin{tabular}{|c|c|c|c|c|}
\hline \multirow[b]{2}{*}{ Age (y) } & \multicolumn{3}{|c|}{ Years from first exposure } & \multirow[b]{2}{*}{ Total } \\
\hline & $<5$ & $5-14$ & $\geqslant 15$ & \\
\hline $\begin{array}{l}15-24 \\
25-34 \\
35-44 \\
45-54 \\
55-64 \\
65-74 \\
\geqslant 75\end{array}$ & $\begin{array}{r}1676 \\
1922 \\
863 \\
290 \\
37 \\
-\quad 4\end{array}$ & $\begin{array}{r}M e r \\
522 \\
4559 \\
3246 \\
1496 \\
340 \\
38 \\
6\end{array}$ & $\begin{array}{r}- \\
309 \\
2780 \\
3075 \\
1615 \\
305 \\
55\end{array}$ & $\begin{array}{r}2198 \\
6790 \\
6889 \\
4861 \\
1992 \\
347 \\
60\end{array}$ \\
\hline Totals & 4792 & 10207 & 8138 & 23136 \\
\hline $\begin{array}{l}15-24 \\
25-34 \\
35-44 \\
45-54 \\
55-64 \\
65-74 \\
\geqslant 75\end{array}$ & $\begin{array}{r}283 \\
342 \\
212 \\
34 \\
- \\
-\end{array}$ & $\begin{array}{r}\text { Wom } \\
67 \\
864 \\
701 \\
326 \\
46 \\
-\quad \\
-\quad\end{array}$ & $\begin{array}{r}- \\
59 \\
616 \\
830 \\
590 \\
98 \\
11\end{array}$ & $\begin{array}{r}350 \\
1265 \\
1528 \\
1190 \\
636 \\
98 \\
11\end{array}$ \\
\hline Totals & 871 & 2004 & 2203 & 5078 \\
\hline
\end{tabular}


Table 2 Observed $(O)$ and expected $(E)$ numbers of deaths from major causes among employees

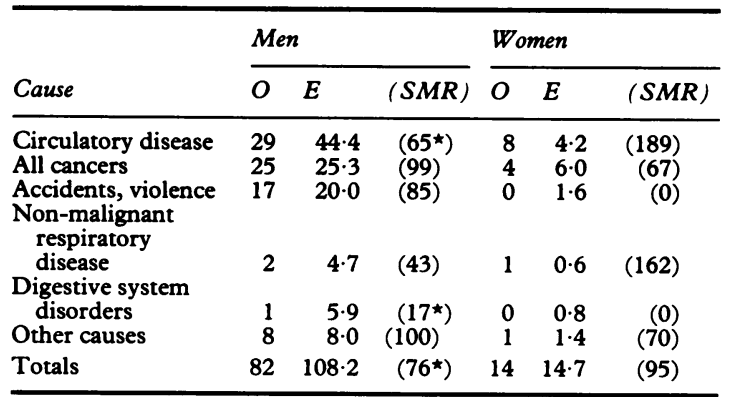

${ }^{\star} \mathrm{p}<0.05$.

achieved. Those neither traced nor identified as dead were assumed to be alive, so mortality may be slightly underestimated. Eighty two men and 14 women had died.

The two groups of assessors generally agreed on the degree of dustiness of different jobs at different times; of 101 evaluations, 76 were the same or within one point on the six point scale used. A "sensitivity analysis" using either set of ratings when they differed had little impact on the results.

Table 1 shows the distribution of person-years by age and time since first exposure to dust. Over one third of time in the study occurred beyond 15 years from first exposure.

Dust samples were taken between 1979 and 1987 and analysed using the method recommended by the National Institute of Occupational Safety and Health for measuring concentrations of fibrous glass. ${ }^{6}$ The time weighted averages (based on roughly 20 personal samples in each area) were between 0.02 and $0.05 \mathrm{f} / \mathrm{ml}$ (geometric means were slightly lower). The highest value observed for any sample was $0.91 \mathrm{f} / \mathrm{ml}$. The proportion of fibres that are glass is unknown.

Table 2 describes the major causes of death for each sex. For no category was any excess significant. Overall mortality among men was significantly below

Table 3 Observed $(O)$ and expected $(E)$ numbers of deaths from lung cancer among employees by cumulative exposure to dust and by time since first exposure

\begin{tabular}{|c|c|c|c|c|c|c|}
\hline \multirow{3}{*}{$\begin{array}{l}\text { Cumulative } \\
\text { exposure } \\
\text { to dust }\end{array}$} & \multicolumn{6}{|c|}{ Time since first exposure (y) } \\
\hline & \multicolumn{3}{|c|}{$<15$} & \multicolumn{3}{|c|}{$\geqslant 15$} \\
\hline & $O$ & $E$ & $(S M R)$ & $O$ & $E$ & $(S M R)$ \\
\hline $\begin{array}{l}<5 \\
5-9 \\
10-24 \\
\geqslant 25\end{array}$ & $\begin{array}{l}1 \\
1 \\
1 \\
1\end{array}$ & $\begin{array}{l}0.3 \\
0.5 \\
0.6 \\
0.5\end{array}$ & $\begin{array}{l}(339) \\
(206) \\
(162) \\
(193)\end{array}$ & $\begin{array}{l}1 \\
2 \\
2 \\
2\end{array}$ & $\begin{array}{l}0.7 \\
1.3 \\
1.2 \\
3.0\end{array}$ & $\begin{array}{r}(138) \\
(156) \\
(171) \\
(67)\end{array}$ \\
\hline Totals & 4 & 1.9 & (209) & 7 & $6 \cdot 2$ & (114) \\
\hline
\end{tabular}

$\star$ Based on averaged estimates; see text for details.
Table 4 Observed $(O)$ and expected (E) numbers of deaths from lung cancer among employees by cumulative exposure to dust (with a five year lag) and by time since first exposure beyond five years

\begin{tabular}{|c|c|c|c|c|c|c|}
\hline \multirow{3}{*}{$\begin{array}{l}\text { Cumulative } \\
\text { exposure to dust } \\
(5 \text { year lag })^{\star}\end{array}$} & \multicolumn{6}{|c|}{ Time since first exposure (y) } \\
\hline & \multicolumn{3}{|c|}{$5-14$} & \multicolumn{3}{|c|}{$\geqslant 15$} \\
\hline & $O$ & $E$ & $(S M R)$ & $O$ & $E$ & $(S M R)$ \\
\hline $\begin{array}{l}<5 \\
5-9 \\
10-24 \\
\geqslant 25\end{array}$ & $\begin{array}{l}0 \\
1 \\
2 \\
0\end{array}$ & $\begin{array}{l}0.4 \\
0.5 \\
0.6 \\
0.1\end{array}$ & $\begin{array}{r}(0) \\
(216) \\
(315) \\
(0)\end{array}$ & $\begin{array}{l}1 \\
2 \\
2 \\
2\end{array}$ & $\begin{array}{l}0.7 \\
1.3 \\
1.3 \\
2.9\end{array}$ & $\begin{array}{r}(128) \\
(152) \\
(160) \\
(70)\end{array}$ \\
\hline Totals & 3 & $1 \cdot 7$ & (181) & 7 & $6 \cdot 2$ & (114) \\
\hline
\end{tabular}

^Based on averaged estimates with last five years' exposure ignored; see text for details.

that expected $(S M R=76, p=0.012)$ as was death from circulatory disease. This was apparently not due to a "healthy worker effect," as the SMR for the period beyond 15 years from first exposure (77) was only slightly higher than that for overall mortality. Among women the number of deaths was close to that expected. The greatest excess occurred for circulatory diseases, but it was not significant $(p=$ 0.07 ). Deaths from cancer in women were fewer than expected. No cases of lung cancer were found in women and hence analysis related to this was for men only.

The two deaths from non-malignant respiratory disease were fewer than expected. For lung cancer, however, 11 cases were found compared with 8.1 expected $(S M R=136)$, and proportional mortality (given the low all cancer SMR) was high. For this reason, the data were divided by time since first exposure to dusts and cumulative dose (table 3 ). This showed a higher SMR in the shorter latency period, although the number of cases was small. Further, there was no trend towards an increasing SMR with increasing cumulative exposure to dust.

Analysis of data omitting the first five and the last five years of exposure to dust showed no pattern of increasing risk with increasing exposure (table 4).

\section{Discussion}

The results appear to confirm those of other studies, which have not found increased mortality-from lung cancer or other causes-associated with manufacturing glass filaments (textiles). Several points are, nevertheless, worthy of comment as follows.

We did not have data on smoking habits. The low mortality, however, from circulatory and non-malignant respiratory diseases suggests that it was not higher than the norm for the province. Local mortality, which might at least partially adjust for smoking habits, was below the provincial average. From 1973 to 1979 the death rate in Guelph, where the plant is located, was $6 \%$ below that in Ontario, 
and lung cancer among men aged $35-69$ was $2 \%$ less. $^{7}$ This had a negligible effect on the results.

The dust estimates were based on memory, rather than measurement, and although we treated them as interval data, they may have been little more than ordinal. Also, estimates provided by management and by hourly paid (union) employees, although mostly in agreement, were sometimes highly discrepant. Recalculation of the exposure response relation, however, using either set of estimates rather than the average made no appreciable change.

The dust levels recorded were low, despite the fact that sampling concentrated on areas where the worst conditions were expected; these levels may not be typical of all plants. It should be emphasised, however, that the method used only coated fibres which were thinner than $3.5 \mu \mathrm{m}$ diameter and larger than $10 \mu \mathrm{m}$, and did not discriminate between glass and non-glass fibres.

The site of one cancer was miscoded as shoulder rather than lung; it would have been inappropriate to reclassify it as a lung cancer, and the effect on the exposure response relation would have been small.

The cohort included all subjects who met the eligibility criteria, but the numbers were nevertheless relatively small. For the male cohort as a whole, the power to detect a significant increase was $80 \%$ if the true effect was slightly more than a doubling of the risk of lung cancer.

We thank Fiberglas Canada Inc for their support; the Amalgamated Clothing and Textile Workers' Union for their help; and the steering committee for its $\stackrel{?}{\Rightarrow}$ participation. To Statistics Canada we extend our thanks for their invaluable help. The Ontarioo Ministry of Transportation and Communications provided access to data on drivers' licences.

Requests for reprints to: H S Shannon, Occupational Health Program, McMaster University Health Sciences Centre, Hamilton, Ontario L8N 3Z5, Canada.

1 Doll R. Symposium on MMMF, Copenhagen, October 1986: $\infty$ overview and conclusions. Ann Occup Hyg 1987;31:805-19. iv

2 Simonato L, Fletcher AC, Cherrie JW, et al. The International $\omega$ Agency for Research on Cancer historical study of MMMF production workers in seven European countries: extension of the follow-up. Ann Occup Hyg 1987;31:603-23.

3 Enterline PE, Marsh GM, Henderson V, Callahan C. Mortality update of a cohort of U.S. man-made mineral fibre workers. Ann Occup Hyg 1987;31:625-56.

4 Shannon HS, Jamieson E, Julian JA, Muir DCF, Walsh C. Mortality experience of Ontario glass fibre workers-extended follow-up. Ann Occup Hyg 1987;31:657-62.

5 Case RAM, Lea AJ. Mustard gas poisoning, chronic bronchitis and lung cancer. British Journal of Preventive and Social Medicine 1955;9:62-72.

6 National Institute for Occupational Safety and Health. Criteria for a recommended standard . . . occupational exposure to fibrous glass. Washington: United States Department of Health Education and Welfare, 1977.

7 National Health and Welfare. Mortality atlas of Canada. Vol 3. Urban mortality. Ottawa: Minister of Supply and Services (D) Canada, 1984.

Accepted 8 January 1990 